\title{
EN TORNO A LA NOCIÓN DEL SER EN ORTEGA. Acerca de algunos interrogantes e incertidumbres que se plantean en los vectores ontológico y epistemológico de la filosofía orteguiana.
}

\author{
Luis GARCIA AGUILAR
}

\section{Introducción}

En el tratamiento de la temática denotada por el título se hacen perceptibles determinadas dificultades, cuyo origen radica tanto en la novedad de sus contenidos como en cierta dosis de tensiones internas que afectan al sentido y significado de la noción del ser. Sobre la teoría de referencia se deslizan razonables dudas, condensadas en diversos núcleos de problematismo a los que no parece fácil hallar apropiada solución. La lectura de los correspondientes textos deja un cierto sedimento de insatisfacción que nos induce a tratar, en primer término, de acceder a una comprensión cabal de la expresada noción, condición indispensable para captar la auténtica dimensión del problema. Empero, se puede aventurar la persistencia de una cierta oscuridad que no dejará de afectar a la cohesión interna de las soluciones propuestas por el filósofo madrileño. Todo ello, por supuesto, más allá de las genuinas aportaciones contenidas en sus tesis metafísicas. Es un tema en el que vemos implicadas algunas cuestiones surgidas de la consideración filosófica de la ciencia contemporánea. Matiz éste que le confiere una actualidad todavía no desdibujada, por lo que acaso no sea del todo inútil acometer una cierta tarea de clarificación.

La teoría del ser, eje de una atención compartida con su conjugada metafisica del conocer, se sitúa — como el mismo Ortega sefiala ${ }^{1}$ - en el foco central de la filosofía. Constituida en clave de bóveda de su concepción, se muestra

1 P. e., en QV, pág. 142. Véase nota bibliográfica al final. 
como uno de los vectores temáticos más relevantes dentro del pensamiento de nuestro filósofo ${ }^{2}$. Su carácter fundamental conlleva que los problemas suscitados en su esfera se proyecten sobre el conjunto de su doctrina filosófica. Mas habremos de limitarnos a reflejar sólo algunas de las múltiples facetas que presenta la cuestión, lo que quizá también contribuya a hacer transparente dónde radica y en qué consiste, realmente, el núcleo de las dificultades expresadas.

\section{Esbozo de la tesis orteguiana acerca del ser}

En primer término, acometemos la tarea de bosquejar, a muy grandes rasgos, los aspectos más peculiares que configuran la citada teoría. Como reelaboración personal, inevitablemente incompleta, una necesaria simplificación situará en primer plano determinados puntos, dejando difuminados o en la sombra otros importantes matices o facetas. Es obligado destacar que nos hallamos ante una teoría sutil y complicada, sometida a la propia evolución de su pensamiento. Centramos el análisis en su concepción del ser expuesta a partir del año 29, donde surgen, a nuestro modo de ver, los rasgos de mayor problematismo, sin que esto signifique la ausencia de antecedentes, como puede verse, p. e., en Investigaciones psicológicas (XII, 383/384). Aunque dispersa dicha concepción a través del conjunto de su variada producción, vamos a servirnos, preferentemente, de los textos contenidos en el libro ¿Qué es conocimiento?, cursos universitarios impartidos en torno al inicio de la década de los años treinta y no incluidos en sus Obras completas, donde sus ideas sobre el tema adquieren especial densificación. En trabajos posteriores, a los que en aras de una más eficaz exposición no renunciamos a utilizar, se reiterarán dichas nociones que permanecerán ya, en lo

2 De su amplio estudio por la crítica, por obvias limitaciones de espacio sólo vamos a sefialar, dada su particular significación para los contenidos especificos aquí tratados, el interesante artículo del profesor Ramón RODRfGUEZ, "Ortega y la reforma de la noción de ser" (Anales del Seminario de Metafisica, vol. XVIII. Ed. Universidad Complutense. Madrid, 1983), donde su autor aborda el asunto con la amplitud requerida para obtener una visión general. Al poseer un fondo temático común, nuestro propio desarrollo no puede dejar de tener puntos de contacto con el referido artículo, si bien los creemos esencialmente tangenciales. La perspectiva adoptada en estas páginas difiere, principalmente, por enfocar su objeto bajo un ángulo mucho más estrecho - centrado en las dudas y ambigüedades cuya existencia se recogen en el citado trabajo- lo que acota las dimensiones del espacio teórico considerado. Sin embargo, la diferencia se acentúa al considerar la mayor dosis de perplejidad que se halla tras la indagación aquí emprendida. 
substancial, sin modificación. Limitándose, en todo caso, a una labor de matización y pulimento.

Cabe cifrar el objetivo último de la empresa orteguiana en una superación de la Modernidad. Traspasar, pues, la órbita del idealismo, aunque conservando, al tiempo, tanto sus elementos de verdad como los contenidos en el realismo, la otra gran tradición filosófica. Esta explicitada finalidad se acomete sirviéndose de su bien conocida afirmación acerca de la vida como realidad radical convertida en eje fundamental de sus tesis filosóficas. Vida que consiste en lo que al hombre le pasa con lo que le rodea y afecta y para lo cual Ortega utiliza el término circunstancia. Esta coexistencia, indisoluble y dependiente, del hombre y las "cosas" - la proposición básica de nuestro filósofo-, la expresa en su célebre fórmula "Yo soy yo y mi circunstancia», que viene a resumir su pensamiento. Actuación mutua entre hombre y "cosas», entendiendo por éstas simplemente los "algos ahí» con que aquél se relaciona, que es originaria y primariamente una relación espontánea de vivencia, de carácter antepredicativo o preteorético. Este contexto vital o, dicho de otra manera, ese ocuparse con las cosas en que consiste la vida, "no es primariamente cognoscitivo" ( $R R$, 93). La circunstancia, conjunto de todos los «algos ahí", constituirá un conjunto de "facilidades y dificultades" para la vida. Dentro de este ámbito, el ser de las cosas consistirá en puro ser instrumental, actuante of funcionante, un ser para el sujeto. Éste será el ser primario de las cosas y de su conjunto, el mundo: un ser relacional en cuyo foco se halla el sujeto. Desde luego, si como pura descripción de la realidad se define el ser de este modo; si consiste en ser relación a un sujeto, es evidente que las cosas no tienen un ser independiente del hombre. Conviene advertir que sobre esta noción de independencia gravita la crítica a las diferentes posiciones de la tradición filosófica, como en múltiples de sus exposiciones se pone de manifiesto. Correlativamente - podemos agregar-, la mayoría de los equívocos que nos saldrán al paso van a girar en torno a la idea de dependencia. Así pues, como reitera en numerosas ocasiones, "las llamadas "cosas" circunstantes, o mundo, no tiene un ser por sí, substante, independiente de mí" $(Q V, 112)$. Ser primario es lo que en otros lugares también denomina ser ejecutivo, que "sólo existe mientras actúa y según actúe» (QV, 122). Sintetizando, dichos "algos" o "cosas", en esta relación vital que todavía no implica teorización alguna sobre ellas, "son originariamente puras actuaciones sobre $\mathrm{mi}$ en cuanto viviente, esto es, que son facilidades o dificultades y nada más» (QV, 122). De este modo, la consideración de cosa, en la significación que nos es habitual, es ya pura interpretación, y no vivencia, 
que proyectamos sobre ellas. Anadamos que, viceversa, el ser o consistir del hombre es, igualmente, pura ejecutividad sobre la circunstancia. Aquél sólo es, pues, en la medida en que actúa "sobre y con las cosas". Se trata de la interdependencia esencial que radica en la base de su doctrina filosófica.

Ahora bien, cuando en la ocupación compleja con las cosas que componen la circunstancia - por más que ésta no sólo de cosas se compone, y aunque aquí, para simplificar, a ellas nos reducimos-, ocurre que el hombre «experimenta una dificultad en el trato con ella, una falla, una limitación, un estorbo» (RR, 89). Según nuestro filósofo, acontece entonces que el hombre cae en la cuenta de que "eso ahí" es una cosa, es decir, algo que "tiene realidad propia", "un existir propio, una índole suya" que posee al margen de mí. Surge, así, la pregunta por el ser en sí o para si de la cosa. Y, extendiendo la pregunta a las relaciones que unen a las cosas entre sí, nos hallamos ante la pregunta por el ser del mundo, del universo.

Mas este ser o consistir en sío propio de las cosas no es algo que se encuentre patente en las cosas u objetos con que nos ocupamos al vivir. El ser se halla más allá de lo que las cosas nos muestran. Se halla latente, conformando un trasmundo al que tenemos que dirigir nuestra atención para averiguar en lo que las cosas consisten. Nos las habemos ya con una actividad del hombre, pregunta intelectual sobre el mundo y sus elementos, si bien de carácter estrictamente vital, que ocupa únicamente un pequeño segmento de nuestra vida. Es la actividad teorética, donde pensamos acerca del ser latente de las cosas, pues éstas ya las tenemos delante, facilitando o dificultando nuestra vida, y cuyo resultado es el conocimiento. Junto al ser primario, instrumental, ejecutivo, tenemos ahora el ser objetivo, el ser pensado, atribuido a las cosas debido a la necesidad de "saber a qué atenernos" respecto a ellas para poder fijar de antemano nuestra conducta. Asi, desde el desconocimiento previo tratamos de anticiparnos "a las cosas mismas, mediante una imagen o esquema en que se nos revela su contextura definitiva" $(\mathrm{QV}, 151)$ y que nos proporciona "aquella imagen de ella que nos da seguridad vital con respecto a ella" (QV, 152). Muéstrase con claridad cuál es la función que en nuestra vida desempeña el ser de las cosas. La noción del ser queda, de esta manera, escindida en dos áreas de desigual valoración.

El ser objetivo se presenta en la filosoffa orteguiana con un carácter secundario, comparado con el principal que atribuye al ser instrumental, ejecutivo. Se trata de una actitud coherente, puesto que este último es el que configura 
nuestra actividad primaria, espontánea, la que se ejercita en la vida preteorética u ocupación no cognoscitiva, en sentido estricto, a la que casi siempre se cuida de calificar de originaria y primordial. Aunque el ser objetivo es el correlato de una ocupación también vital, la actividad teorética que tiende al conocimiento adquiere, no obstante, una consideración subordinada y de importancia menor respecto de la originaria vivencia ejecutiva.

\section{Delimitación de los aspectos más problemático}

La tesis principal, referida ya al ser objetivo de las cosas, correlato de lo que tradicionalmente se estima como conocimiento, mantiene sin variación la dependencia del ser de las cosas respecto del sujeto. Aun situado ahora el problema en un ámbito diferente, un mismo norte orienta la solución. La ocupación cognoscitiva con las cosas, que acaece en el plano teórico, es tan vida como cualquier otra forma de relación que con ellas mantenemos y, como afirma nuestro autor: "Sigue, pues, el ser de lo que me rodea consistiendo en su referencia a mí, en su actuación vital sobre $\mathrm{mí}^{\prime}(\mathrm{QV}, 122)$. Así, lo que bajo otro sentido designamos como "su independencia de mí no deja de ser sino "un modo de depender de mi actuación, a saber, algo es lo que es cuando yo actúo teoréticamente sobre ello" (QV, 125). Tenemos, pues, que el ser objetivo de las cosas consistirá sólo en una de las particularizaciones del ser primario, ejecutivo de las cosas. La conclusión inmediata de esta paradójica posición es que no hay ser al margen y aparte del sujeto. La magnitud del asunto queda perfectamente subrayada por Ortega: «El error más grande de toda la tradición filosófica hasta Kant ha sido presumir que las cosas tienen un ser ellas por sí, por su cuenta y riesgo» (QV, 153-154). Estamos ante una idea directriz, convertida en hilo destacado de su entramado conceptual y como tal la vemos aparecer con asiduidad en las páginas de su obra. Nos limitaremos a un breve apunte de su opinión, donde quedan resaltadas sus aristas principales. Con la reserva de que tal vez haya que considerar al animal un "casi-hombre", taxativamente afirma al respecto: "Fuera del hombre no hay ser... Por eso no está ahí; antes bien, para que lo haya tiene el hombre que buscarlo. En esta busca nace precisamente el ser" (QV, 153).

Completemos la fisonomía de la noción del ser, así esbozada, con el perfil que adquiere su función. Modo de proceder necesario porque el filósofo madrileño, en el tratamiento del problema del ser, acentúa su funcionalidad. 
Incluso, a veces, cabe preguntarse si no introduce algún grado de indefinición, al no separar con claridad la función del ser, de su estructura constitutiva. La indagación sobre el ser es una necesidad con la que el hombre se encuentra en su vida. Se trata, en definitiva, de una respuesta a un imperativo de orden vital: "Porque las cosas nos aprietan inexorablemente antes de que pensemos en ellas nos vemos obligados a buscarles un ser y a descubrir o construir éste" (QV, 156. Los subrayados son nuestros). Nos vemos llevados a construir el ser - «idea» o "noción" - de las cosas, puesto que éstas, en cuanto tales, las tenemos ya presentes, delante nuestro, constituyendo el mundo. $Y$ así, este ser de las cosas no consistirá en otra "cosa", parangonable a las existentes; ni tampoco en una especie de "hipercosa», depuración sofisticada de aquéllas. El ser es algo radicalmente distinto, que adquiere la consistencia de "un esquema intelectual" y la proposición en él contenida "nos expresa o descubre lo que una cosa es» (QV, 157). A lo que añade nuestro filósofo, recalcando su carácter funcional: " $Y$ «lo que una cosa es" está constituido siempre por el papel que la cosa representa en la vida, por su significación ultravital» $(Q V, 157)$. Con ello, Ortega apunta de nuevo hacia el modelo del ser primario, del ser para mí, subrayándose de esta forma el aspecto problemático de su particular tesis ontológica con la inserción de una funcionalización, quizá un tanto excesiva, antes aludida.

Por lo que a la concomitante dimensión gnoseológica se refiere, nuestro hilo temático nos conduce hacia otra faceta problemática no menos interesante. De las características de que venimos haciéndonos eco, adscritas al ser o noción de las cosas y de su conjunto máximo, o universo, concluirá el filósofo madrileño que el conocimiento consiste en una "interpretación" que el hombre hace de la realidad y cuyo producto es, como no deja de insistir, una ingente construcción. Constructivismo del conocimiento que conduce a una inquietante reflexión. Nuestro pensamiento de la realidad no es la realidad. La realidad "auténtica y primaria" ha quedado cubierta por las sucesivas capas de interpretaciones elaboradas por el hombre a lo largo de su historia. Son, como el filósofo dice, "todas esas creencias de ahora y de otros tiempos" (IC, V, 399). Esta producción intelectual se ha convertido en un velo que oculta la faz desnuda de la realidad. Para captar la pura imagen de sí misma sería necesario, en primer término, levantar ese velo encubridor. Mas se infiere que el subsiguiente intento de contemplarla cara a cara se halla condenado al fracaso. Sólo logramos tejer otra interpretación más, que, de forma inexorable, siempre la vuelve a encubrir. Nos hallamos frente a un mundo cuyo ser consiste en "un puro enigma" (LM, XII, 86). El ser asumirá, en las coordenadas del pensamiento orteguiano, la faz de "lo constitutivamente oculto, lejano, distante y ausente; en suma, lo misterioso 
o enigmático por excelencia" ( $R R, 85)$. Y lo que de modo subyacente queda planteado es el abismo gnoseológico que se abre ante el hombre en su camino para llegar a aprehender el ser de las cosas. Una sombra de duda se cierne sobre la pretensión de certeza del conocimiento, cuya validez nuestra cultura occidental no cuestiona, "no obstante - según afirma Ortega-, carecer de todo dato inmediato y directo sobre él» ( $R R, 85)$. Por razones de oportunidad, dejemos ahora esta última consecuencia simplemente apuntada.

Desde una perspectiva centrada, no en las cosas, sino en su ser, esta teoría metafísica se acerca a la noción kantiana del ser en sí. Se trata de un ser que no se da al sujeto, que éste no encuentra en las cosas con las que se ocupa y en que consiste su vivir. De hecho, la visión del ser como poner de un sujeto la subraya Ortega como lo "ultravivo" del kantismo, en su "Anejo a Kant", de 1929, primer trabajo donde expone las tesis resultantes de su empresa del "replanteamiento del problema del ser", acometida desde 1925, como expondrá en su trabajo más autobiográfico "Prólogo para Alemanes», de 1934.

Nos hallamos, por consiguiente, ante una paradójica visión del ser o consistencia de las cosas, convertida en decisivo nervio doctrinal. En este estrato del ser abjetivo - correlato del conocimiento, pero que no se limita a éste, pues tras él vislumbramos un rasgo ontológico- vuelve a reproducirse, bien que a otro nivel, idéntico esquema que el aplicado a la consistencia dependiente del yo y del ser primario de las cosas, operante en la vida preteorética. En el orbe de la teoría, donde cabe hablar de un ser por si de las cosas, éste sólo aparece tras la pregunta por el ser que el sujeto lleva a cabo. La ausencia del sujeto implica la inexistencia del ser, consistente en respuesta a tal interrogación. $\mathrm{O}$, como Ortega dice, "el ser sobreviene a las cosas cuando y porque el hombre se pregunta por él" (QV, 164). Se destaca al máximo una relación de mutua dependencia, donde el problema del ser oscila, desde el hombre a las cosas y viceversa. Por supuesto, Ortega asumía con plenitud el carácter de paradoja que su propuesta metafísica implicaba. En sus propias manifestaciones tenemos el mejor comentario sobre el asunto:

"Se trata, pues, nada menos, de invalidar el sentido tradicional del concepto "ser", y como es éste la raíz misma de la filosoffa, una reforma de la idea del ser significa una reforma radical de la filosoflan (QF, VII, 394).

Tampoco dejaba de insistir acerca de la novedad de su aportación térica y en las dificultades que presentaba aun su mera compresión. Así, se multiplicaban 
las reservas que se oponían a su completo reconocimiento. Este trabajo de entendimiento previo, de cara a su aceptación, es ocasión para que manifieste su sospecha de que

"por unas u otras causas, hay en nosotros una propensión primaria a admitir la tesis contraria, según la cual el ser es la cosa, está en ella, pertenece a ella sola; y que esta tendencia nativa se habrá consolidado en tradición y hábito mental milenario contra el que nos cuesta buen trabajo reobrar» (AHF, 165).

La otra cara de la moneda de esta temática, donde se hacen patentes algunos elementos poco inteligibles, se exhibe en la dimensión del conocer. Ortega no duda en calificar a su tesis gnoseológica como «la modificación más radical que cabe en la teoría del conocimiento hasta nuestros días" (RH40, XII, 233). Su concepción viene a transformar completamente la función del pensamiento, de la inteligencia en la tarea del conocer, subvirtiendo la relación íntegra entre la inteligencia humana y la realidad. El filósofo destaca con énfasis que los contenidos intelectuales, producto de nuestra actividad cognoscitiva, no son reflejo de la propia realidad, sino que se reducen a una función instrumental que, meramente, nos ayuda a "hacernos patente la realidad" (RH40, XII, 233). Ilustra la diferencia entre la realidad y nuestra concepción sobre ella comparándola con la existente entre un paisaje real y el plano topográfico - «esquema irreal»-, que hasta aquél nos conduce. Las dudas arrojadas sobre la propia posibilidad del conocimiento de la auténtica realidad —aspecto sobre el que se hará necesario volver-, nos empujan a un camino sin retorno que Ortega ha recorrido en buena medida. La ciencia no será ya - a sus ojos- conocimiento de la realidad, al menos en el sentido pleno de penetración del objeto por la mente del sujeto, como la tradición lo había venido definiendo. En coherencia con esta nueva visión, desde la que las cosas «ni tienen por sí su ser, ni nos proporcionan su conocimiento", es perfectamente concebible su reconocimiento de que "La paradoja es fantástica, ... Vuelve boca abajo todos los hábitos más consolidados de la interpretación del ser y del conocer que, en su primer estadio, conserva la filosofian (AHF, 178).

A la vista de lo anterior, en efecto, la primera impresión que nos asalta es de extrafieza. Su sentido global se muestra esquivo. De ahí que intentemos aclarar los equívocos o contradicciones que nos parece ver implicados, emergentes a lo largo dos ejes, en cierta manera paralelos. En primer término resalta el problema 
en la dimensión ontológica, consistiendo en la disociación que el filósofo lleva a cabo entre la cosa y su ser. $\mathrm{Si}$, como taxativamente afirma, el ser es algo que no está en la cosa, y que tampoco consiste en cosa o hipercosa alguna, en principio el asunto incita a la perplejidad. Se ha producido una distorsión del sentido que el ser poseía para el pensamiento filosófico tradicional. En el contexto acotado por éste, podría el ser hasta mostrarse incognoscible, pero el ser en si acusaba un sentido de pertenencia, de constituir parte - las más central e importante- de la cosa u objeto, aquélla que le dotaba de su propia identidad. El movimiento mental inmediato a ese nuevo aspecto tan insólito es preguntarse si nuestro pensador designa con dicho vocablo "ser" ese algo que hasta entonces había sido su indiscutido correlato. Mas un recorrido por las páginas de sus obras más emblemáticas pronto nos convence de que así ocurre. En efecto, todas las referencias textuales, de significado convergente, quizá se podrían resumir en sus palabras sobre la «esencia de la cosa»: "aquello en esta de que pueden enunciarse proposiciones con verdad invariable o eterna" (IPL, VIII, 178). Un ejemplo, reiterado por Ortega en diversas ocasiones, puede contribuir a disipar cualquier vacilación. Contraponiendo al ser primario, instrumental por tanto, de la luz, cuyo sentido se agota en su "alumbrarnos», manifiesta que el ser o esencia, el ser en si de la luz, "consiste en vibraciones del éter, o en un estado del campo electromagnético" (QV, 112).

Recapitulando un tanto, advertimos que el ser consiste en «un supuesto y una construcción" (QV, 120), "concepto" o "esquema intelectual", de lo que cabe concluir que "pensar es interpretar la realidad" (QV, 117). Nos movemos en el terreno de una labor intelectual de interpretación, de una hermenéutica. El producto de esta actividad consistirá en el ser de las cosas, que resultará una construcción, una teoría hipotética, en suma, un poner el ser del universo por parte del sujeto. Respuesta ésta que, así expresada, queda incompleta. Porque, como construcción pura, la colocaría, ipso facto, en un puro subjetivismo, decantación de una modernidad que nuestro filósofo se empeñaba en superar. Sin embargo, será el elemento objetivo el que nos plantee los mayores interrogantes. El camino que desde el mundo de las cosas conduce a su ser se halla afectado —ello es palpable en los textos - por una cierta indefinición. Parece que Ortega no se decide a situarlo con precisión, quedando como inmerso en una onda de fluctuación que nos impide enfocarlo con nitidez. Adelantemos ahora que se nos escapa, pura y simplemente, cuál es su verdadera ubicación en este contexto del ser. Recogemos, p.e., una de sus afirmaciones, en principio diáfana, mas cuya claridad se revela ilusoria. En analogía con el acto de 
"creación», o construcción del carpintero, cuando produce una silla que no se hallaba en el tronco del árbol utilizado, manifiesta: «así el pensamiento con las cosas inmediatas de nuestra vida fabrica el ser de esas cosas" (LM, XII, 85. Los subrayados son nuestros).

\section{El carácter histórico de la hipótesis del ser}

Enfoquemos a continuación esa característica, central en la tesis de nuestro autor y constituida en hilo permanente de su entramado conceptual de madurez, del constructivismo inherente a la noción del ser. Diseminados a lo largo de su obra, se pueden encontrar textos dedicados al tema. Por nuestra parte, nos limitamos a señalar, p.e.: «Atisbos de historia de la filosofía», La idea de principio en Leibniz y, singularmente, el "Comentario al Banquete de Platón", sin olvidar sus Notas de trabajo ${ }^{3}$. A través de ellos podemos constatar que Ortega acude a la historia de la filosofia, en particular a sus momentos iniciales, constitutivos. Centra su atención en ver claro - in statu nascendi, como gustaba de decir-, en qué consistía el problema del ser y del conocer para quienes determinaron en gran medida el rumbo futuro de la actividad filosófica. E, igualmente, intenta clarificar cuáles fueron las respuestas que de ellos emanaron. Soluciones que, aunque vetustas, siguen pesando sobre nuestros hábitos intelectuales más arraigados. Es obligado sintetizar la visión orteguiana aunque sea a costa del inevitable deterioro que ello conlleva respecto de las espléndidas páginas dedicadas al tema. Según el pensador madrileño explica, la filosofia tuvo su arranque inicial en el proceso de desvanecimiento del sistema tradicional de creencias, sobre las que comenzó a operar la "duda metódica" - como él la califica - ejercitada por las "minorías alerta" de Grecia, allá por el 600 a. C. Para ese pensamiento mítico-religioso del politeismo griego, la divinidad no sólo se halla fragmentada, sino que fluye hacia las «regiones inferiores» con cierta facilidad, estableciéndose una continuidad esencial desde el hombre a los dioses, pasando por una naturaleza transida a voluntad por la deidad, a cuyos deseos también sirve de expresión. El hombre queda, bajo esta perspectiva, consignado a un mundo donde los seres, las cosas, los objetos, en suma, "lo que hay" constituye una estructura de mediación que lo vincula al

3 Notas de trabajo. Epilogo..., Ed. de José Luis Molinuevo. Alianza Editorial y Fundación Ortega y Gasset. Madrid, 1994. 
estrato superior, numinoso del mundo. Una vez puesto en duda este conglomerado doctrinal de las creencias, uno de los expedientes que la razón pone en marcha para conquistar una nueva concepción —pues en la duda no se puede permanecer-, consistirá en cambiar radicalmente la visión acerca de las cosas del mundo que nos rodea. En adelante, va a cortar los vínculos que venían entrelazando a todas las cosas en una especie de conjunto orgánico animado por espíritus. De este modo, todo cuanto hay, incluyendo al hombre mismo, pasa de una situación de dependencia a convertirse en algo independiente, que tiene su propio ser en sí y que no consiste ya en ser mero reflejo o refracción de otras instancias: ha nacido el ser. Ortega pone de relieve que, en la indagación filosófica temprana acerca de este ser de las cosas, de los objetos otros que el sujeto, se comienza por su desconocimiento. Mas en esta ignorancia se ha filtrado ya la nueva creencia, la de que las cosas tiene ser. El ser se da, pues, como afirmado. Es pregunta que para tener significado, uimplica que sabemos lo que es el ser antes de saber lo que es cada cosa en cuanto que ess (IPL, VIII, 235). Esta idea previa se convierte en causa y efecto, a la vez, de la dualidad larvada que, en adelante, va a afectar a la realidad, a las puras facticidades y a su ser constitutivo. Puesto que de las cosas no conocemos su ser, idea o noción, no cabe el recurso de extraerlo de este ámbito de inmanencia en que consiste el trato cotidiano del hombre con las cosas que componen el mundo. $\mathrm{Y}$, a la inversa, a la hora de acometer la empresa del conocimiento, tampoco podrá seguirse la ruta que a las cosas, a la realidad conduce. Habiendo comenzado la idea del ser como hipótesis extraña a lo empírico, su desenvolvimiento futuro estará marcado por idéntico rumbo. Y así, nos muestra Ortega cómo se ha desarrollado la idea del Ente, sobre todo por parte de Parménides y continuado por Platón, configurada como un modelo ideal, creado a priori por la razón, modelo que se introyecta en las cosas, que, de esta manera, adquieren su carácter de entes, si bien en la limitada medida de su posibilidad. Pues, como es conocido, para estas escuelas de pensamiento filosófico el mundo de lo sensible sólo será un pálido reflejo de la auténtica realidad, siempre situada en otra parte. Alejamiento de lo empírico, por cierto, que - a los ojos de Ortega-, define a la filosofía, actividad intelectual que "comenzb y consiste cualquiera sean sus otras diferencias de escuela - precisamente en negar la jurisdicción de la veracidad a los sentidos" (IPL, VIII, 245). Transcribiendo en "la forma gruesa, pero vivaz», que nuestro filósofo utiliza para caracterizarlo, se debe afirmar que «el Ente no está en los entes, sino al revés, los entes en el Ente" (IPL, VIII, 222/223). Las cosas en cuanto entes, es decir, las cosas en cuanto teniendo un ser, una si-mismidad, deben ceñirse a ese modelo previo, 
irreal que es el ente, cuya esencia consistirá en la conjunción y articulación de una serie de predicados, "atributos previos", "condiciones o requisitos" a priori que las cosas deberán contener para dejar de ser meros "algos ahín y convertirse en entes. El primer «atributo previo» y, sin duda, el eje del modelo, será la independencia del hombre. A éste añade otros: auténtico, verdadero, legítimo. $\mathrm{Su}$ característica principal es que exhiben marcadamente lo que de desideratum humano conlleva el ser, lo que de necesidad implica la pregunta por el ser, como nuestro autor poner muy bien de relieve: "los hombres necesitan que algo sea (con auténtico ser)» (CB, LX, 773). Este armazón construido idealmente, ejemplificado en el Ente parmenídeo o en las Ideas platónicas, se sustenta también en otros conceptos fundamentales, pero que nos parecen girar un tanto, desde la consideración puramente humana aludida, hacia lo característico del objeto, como son la identidad, la permanencia y la invarianza, que van a servir, en adelante, para estructurar aquello que se denominará el ser de la cosa. Como Ortega hace observar, en una de sus notas de trabajo, este ser originario de Grecia "es ya de suyo un cogitatum» ${ }^{4}$. Subraya así una particularidad idealista, reconocimiento de que sólo si es de esta manera - convertirse o ser idea o concepto-, puede ser cognoscible.

Un larvado escollo, sin embargo, dejado a nuestra espalda, amenaza la coherencia lineal de la esbozada visión orteguiana sobre el ser en los albores de la actividad filosófica. Se nos ha deslizado una alusión a la "nueva creencia» en el "ser" de las cosas. Mas no se trata de una arbitrariedad por nuestra parte. Manifestaciones acerca de esta creencia pueden verse en diversos lugares de la obra del filósofo. Según su idea directriz, sólo en ese momento de la historia griega -e. d., en una determinada encrucijada espacio-temporal-, le fue posible al hombre ponerse a la faena del conocer porque "vivía instalado firmemente en la creencia de que lo real era plena y puramente sers (AP, V, 533). Su concepción historicista del conocer le conduce a afirmar la creencia en el ser como "supuesto" previo, condición indispensable para esta actividad humana del conocer (AP, V, 531). En el artículo, citado ya, del profesor Rodríguez se recoge esta idea de que la noción de Ente se constituye en aquel entonces como un supuesto, y en cuanto tal "el "ser" de las cosas es ante todo una creencia" ${ }^{5}$, convertida en una "condición de posibilidad del conocer". Esto lleva al autor a conceder - siguiendo a Ortega - que el suelo del ser corresponde a la "propia

4 Notas de trabajo, n. ${ }^{\circ} 437$, pág. 281.

5 Op. cit., pág. 45. 
vida humana, raíz preteorética de toda teoría $»^{6}$. Es decir, que la cuestión del ser, transformada en creencia, por el mismo carácter intrínseco de ésta, pasa a radicarse en el subsuelo del psiquismo, morada de lo latente, erigido en fundamento que concede plena inteligiblidad a todo sistema de ideas o teorías. Traspaso de ámbitos que posibilita un nexo de unión al permitir anclar la actividad teorética — secundaria, por tanto-, en el fondo vital, primario, antepredicativo. Ahora bien, ¿es ésta la única interpretación posible? En su propia doctrina late una cierta ambivalencia que puede desenfocar un tanto la cuestión. En síntesis, la dificultad entrevista se centra en la acentuación del carácter de creencia que se atribuye a la construcción del ser de las cosas, como ya hemos visto. Mas, de otro lado, la concepción orteguiana sobre las ideas y las creencias también nos deja muy claro que el hombre griego, en un momento muy determinado de su historia, inventa el "ser" como reacción ante una verdadera creencia frustrada. La construcción filosófica del Ente por parte de la razón, «hipótesis inventada por el hombre para interpretar las cosas en torno de él y su propio destino" (IPL, VIII, 234), es respuesta al hundimiento del mundo mítico de las creencias tradicionales, asumiendo la contextura de una idea, en el pleno sentido que tiene como término técnico-filosófico de nuestro autor. Desde los esquemas de conversión mutua implicados en su perspectiva, en modo alguno puede tratarse de una creencia que, en el inicio del pensamiento filosófico en torno al "ser", venga a sustituir a otra creencia. Necesariamente, deberá transcurrir un lapso de tiempo indeterminado para que una idea, una construcción teórica, se filtre al fondo vital de los hombres y se transforme en creencia, conformadora de realidad. Y aun esta conversión tampoco deja de suscitar incertidumbre en cuanto al grado que puede alcanzar y si su desdibujamiento como idea llega a ser enteramente completa para los hombres de tiempos posteriores. Habría aquí que tener en cuenta diferentes modelos de creencias, particularmente en cuanto a su génesis. Lo que por mi parte deseo resaltar es que, en principio, la teoría del Ente, la pregunta por el "ser» es pura construcción, idea por tanto y no creencia. Nacida como idea, convertida históricamente en creencia, quizá sin pérdida total de su origen teórico, vuelve de nuevo, en nuestro tiempo - mejor dicho, en los de Ortega - a mutar en puro producto del pensamiento objetivo y a dejar de ser realidad. Su comienzo y su epílogo - a los ojos del filósofo madrilefio - no dejan lugar a duda. Salvo en el tiempo histórico en que haya operado como creencia, es originariamente resultado de la actividad secundaria

6 Op. cit., pág. 46. 
del pensar racional, obra de la razón teorética y no cabe instalarlo concluyentemente en el ámbito vital primario y antepredicativo.

En definitiva, la visión innovadora de Ortega viene a destacar que la función de tal indagación queda marcada por un talante de "universal o absoluta utilidad». La que puede tener para el sujeto, como respuesta a una situación vital, o bien su proyección potencial, su para qué independiente. Esa construcción previa del ente constituye ua parte hominis el Ser y lo que del hombre va en la pregunta" ${ }^{7}$. Por otro lado, la respuesta contendrá a parte rei "los caracteres o notas de la cosa: su Ser» ${ }^{8}$. El núcleo central de esta teoría se hallaría constituido por la conjunción de dos postulados. El ser o consistencia siempre es de la cosa y en modo alguno se trataría de cualquier forma que el sujeto vierta sobre el objeto. Se deduce entonces, aun con la incertidumbre de algunas manifestaciones, que el ser corresponde a la configuración o estructura material y/o energética que dota a cada cosa, objeto o ente de su propia identidad. Ahora bien, el ser de las cosas no mora en ellas, sino tras ellas - como señala con reiteración-, «a ultranza de ellas», constituyendo «un trasmundo, que se halla por su índole inexorable a una distancia absoluta de nosotros... En un lejos radical o absolutamente lejos» (RR, 75). Y así, el ser consistirá en interpretación o esquema intelectual que el hombre construye, fabrica o pone, como respuesta a sus propios interrogantes acerca del sentido, significado y función de las cosas.

La situación paradójica se hace patente en la convergencia de ambos supuestos, cuya misma naturaleza hace sumamente dificil su perfecto ensamblaje en una unidad de sintesis de orden superior.

\section{Modelos explicativos}

Como nos guía el propósito de llegar a entender mejor la noción orteguiana, nos ha parecido interesante enfocar dicha teoría también desde otro ángulo. Con tal fin nos proponemos elaborar un modelo que nos facilite, hasta donde la indole del tema lo admita, una comprensión de carácter casi intuitivo. Ineludible será

\footnotetext{
Notas de trabajo. Epilogo..., n. ${ }^{\circ} 527$, pág. 331.

Notas de trabajo. Epilogo..., n. ${ }^{\circ} 527$, ibid.
} 
añadir que este modelo, como cualquiera otro, opera en un ámbito de pura analogía que nunca podrá ser completa. A pesar de estas limitaciones intrínsecas, proyectadas sobre algunas de las facetas implicadas, estimo que la cuestión esencial queda debidamente tratada, más allá de imposibles afinidades totales. Por otro lado, la teoría de modelos dejó atrás hace ya mucho tiempo - Ortega lo recoge en referencia a la esfera de la ciencia física-, la construcción de reproducciones fieles, de carácter plástico, que nos presentara como un ver casi sensorial la estructura de una realidad no alcanzable ya con los sentidos. En el caso presente el asunto se complica, al integrar en un modelo un determinado aspecto de lo real junto con el producto de la pura actividad subjetiva.

A lo largo de nuestra exposición hemos ido viendo que el ser de las cosas resultaba ser producto de un hacer del hombre, fusión de dos elementos heterogéneos. En el primer movimiento conducente al ser hay un sujeto interrogándose, vuelto hacia sí mismo. Lo primero que del ser tenemos, como no deja de insistir el catedrático madrileño, es una pregunta. El hombre cree que las cosas tienen un ser o contextura, mas puesto que éstas no lo patentizan, fabrícase aquél un ser imaginario, "puro invento nuestro", que sirve como paradigma. Es el Ente, constructo ideal modelado por lo latente de las cosas, traslucido a través de su patencia. El paso siguiente consistirá en la comparación del ser construido con los hechos, con los datos que de las cosas nos proporcionan. Es evidente que de los resultados obtenidos no cabe atribuir a dicho ser idéntica patencia que la mostrada por las propias cosas en nuestra experiencia vital con ellas. A este respecto, por su similaridad potencial, útil para una mejor comprensión, cabe auxiliarnos con la propia noción sobre la ciencia, explicitada por Ortega:

"esta faena es la ciencia; como se ve consiste en dos operaciones distintas. Una puramente imaginativa, creadora, que el hombre pone de su propia y libérrima sustancia; otra confrontadora con lo que no es el hombre, con lo que le rodea, con los hechos, con los datos. La realidad no es dato, algo dado, regalado - sino que es construcción que el hombre hace con el material dado- $\rightarrow(E t G, V, 16)$.

En estos momentos deberemos obviar las particulares dificultades implicadas, a las que dedicaremos unos comentarios posteriores, puesto que el objetivo principal consiste en ver claro, en entender tesis innovadoras.

Los datos brutos, evidenciados en las manifestaciones ejecutadas por las cosas hacia nosotros, los sujetos, son, pues, lo que se compara y evalúa. Bajo la 
perspectiva de la ruta hacia el ser, ahora la comparación es entre los datos de la cosa y el modelo de ser concebido por la mente humana. ¿Cómo describir o caracterizar este modelo ideal, previo al choque con el cual surge el ser? Hemos visto ya que el ser es respuesta de lo real a una pregunta y se trata de un compuesto en que se funden esos dos elementos tan dispares para dar algo así como una figura -ineludible movernos en el terreno de la vaguedad-, plasmación del ser buscado. No resulta fácil proporcionar una idea clara, intuitiva que nos haga ver la estructura de lo puesto por el sujeto. Usando términos puramente analógicos, podríamos decir que dicho Ente, modelo ideal, se configura como una red conceptual o sistema de coordenadas donde se torna posible situar, con sus más diversas gradaciones, toda la amplísima gama de cualidades esenciales que la contextura de las cosas, del universo, pueda contener. No será necesario insistir en que la determinación del ser se acercará más a su realidad a medida que la cuantificación de dichas cualidades gane en precisión y exactitud. Claro que un sistema tal de coordenadas conceptuales no es algo que pueda tener una representación intuitiva, que nos lo haga ver con los sentidos, ni siquiera con los ojos de la mente. De ahí que cualquier modelo explicativo, de forma inexorable, nos deberá quedar muy distante, intraducible a cualquier tipo de representación auténtica. Es posible, p. e., imaginar un sistema vectorial ndimensional en el que cada uno de los vectores corresponda a determinada cualidad, propiedad o característica fijada en su correspondiente magnitud. Cada específico ser o esencia vendría, así, a tener una "representación", que adoptaria una forma o figura cuya estructura vectorial daría en definir ese ser particular. $\mathrm{Ni}$ que decir tiene que seguimos ante algo sin posible representación intuitiva, habida cuenta de la cantidad casi inabarcable de vectores y dimensiones que se precisarían. Este posible modelo analógico nos ha sido inspirado por un trabajo del físico-matemático alemán Hermann Weyl, conocido y citado a otros respectos por Ortega. Se trata de un artículo, contribución de su autor al Handbuch der Philosophie, de R. Oldenbourg, en 1926, posteriormente ampliado y convertido en libro, vertido al inglés ${ }^{9}$ y cuya versión castellana hemos utilizado. En el artículo de referencia, Weyl propone un modelo -entre otros varios- de tipo geométrico para explicar la relación, conjunta y mutuamente dependiente, en que se hallan objeto y sujeto. En forma resumida, se trata de considerar vectores $x$ en un plano, cuya representación numérica o coordenadas

9 Philosophy of Mathematics and Natural Sciencie. Princenton University Press, 1949 (40 reimpresión), 1959. Trad. española: Universidad Nacional Autónoma de México. México, 1965. 
es función de una determinada base, consistente en dos vectores linealmente independientes. Weyl interpreta a los vectores $x$ del plano como «análogos de los objetos en el mundo real»; a las bases, que pueden ser infinitas, como "análogos de observadores reales"; y a los números que expresan las coordenadas como «análogos de los fenómenos subjetivos". Así, las coordenadas asumen, «la apariencia del objeto $x$ para el observador [base vectorial]" Eludiendo extendernos sobre posibles operaciones algebraicas, sólo señalaremos que, según el autor, "coordenadas absolutas de un vector son sus coordenadas relativas con respecto a la base absolutam. Y esta base absoluta no es sino una asignación que efectuamos a cualquier base que elegimos de forma arbitraria.

\section{Las constelaciones como modelo}

A pesar del indudable interés que presenta la referida analogía, hemos intentado escudriñar algunos otros tipos de paradigma que contuvieran mayor afinidad con el núcleo del problema del ser. Creemos haberlo encontrado en otro ejemplo, perteneciente al campo astronómico y producto de una actividad llevada a cabo por el hombre desde tiempos muy lejanos: es la analogía con las constelaciones astronómicas. Una de sus ventajas es la mayor sencillez respecto de los ejemplos anteriormente considerados, a la que se une una gran familiaridad, resultado de ese trato continuo del hombre con los cielos. A la vez, parece hacer plena justicia a casi todos los aspectos de la propuesta orteguiana acerca del ser y de su conocimiento. Por parte del mismo Weyl, cuya lectura por Ortega hacia el año 1927 conviene realzar, se toca este tema, si bien de pasada y desde una óptica diferente a la expuesta en estas páginas.

Una constelación es un artificio creado por el intelecto humano, donde convergen dos géneros de elementos heterogéneos. Por una parte, tenemos un grupo o conjunto de estrellas, elemento objetivo, cuyas componentes se distribuyen en una sección de la esfera celeste. Su forma propia carece de existencia real, es solo efecto de perspectiva. Como afirma el citado Weyl, dicha forma visual de la constelación es «objetivamente indescriptible, sólo intuitivamente experimentable», cuya aparición ocurre «bajo la igualmente indescriptible hipótesis de que yo mismo soy el ojo puntual en $0^{10}{ }^{10}$. Si bien la posiciones de las estrellas admiten

10 Op. cit., pág. 130. Aunque irrelevante para la idea que deseamos subrayar, suficientemente explícita en el texto recogido, aclararemos que ese expresado punto $o$ correspondería a un 
una representación por medio de los diferentes sistemas de coordenadas celestes, desde hace largo tiempo utilizados, y aunque el conjunto de ellas reproduce - con las deformaciones peculiares de cada sistema de proyección- el firmamento, tal como nos aparece, ese particular ingrediente del cielo que son las constelaciones es cosa bastante diferente. Sobre el caos de puntos de luz, formado por estas agrupaciones puramente fortuitas de estrellas, el hombre introduce un orden, una articulación de que las cosas - las estrellas- carecen y que es puramente formal. Desde tiempo inmemorial el mundo estelar visible ha sido receptáculo de múltiples y muy variadas formas y figuras, allí proyectadas por obra de la imaginación; éste es el segmento de subjetividad que el hombre aporta. Por medio de este procedimiento, la constelación deviene un conjunto formal estructurado, donde los datos del universo reciben algo que ellos, por sí, no tienen. Las estrellas están ahí, ante la vista del sujeto, quien sólo puede constatar su aparecer. De entre todo el conglomerado de estrellas visibles en la noche han elegido los hombres algunos grupos cuya visión evoca el recuerdo de figuras familiares. Ya no se trata de un puro hecho de la naturaleza, sino de un hecho interpretado bajo determinadas formas, algunas correspondientes a seres y objetos naturales con los que el hombre entra en relación a lo largo de su vida, tanto individual como colectiva. Aun bajo este prisma de cariz más espontáneamente naturalista, las estrellas en cuestión no dejan de aparecer como simples puntos luminosos que, en el caso más favorable, solo pueden delinear o insinuar una determinada figura, con menor o mayor similitud hacia la de los seres u objetos de referencia. Y, como consecuencia, será del todo necesario que el sujeto acuda a poner todo lo que resta -que, a veces, no es poco- para completar la forma sugerida. El reconocer similaridades entre la forma con que se nos presentan ciertos grupos de estrellas y la figura de determinados seres o cosas — naturales o también artificiales, como la copa, el sextante, telescopio, microscopio, etc.-, nos predispone a pensar que no dejamos de estar en el terreno de una objetividad a la que, simplemente, prestamos nuestra aquiescencia. Aunque no haya tal, esa sensación se desvanece por completo cuando reparamos en que junto a éste, y acaso de mayor relevancia para el particular tema que ahora abordamos, opera otro género de formación que proyecta sobre las estrellas del cielo puras figuras representativas de seres y acontecimientos míticos. Son las constelaciones

observador en la línea de universo de la teoría de la relatividad, en un determinado instante considerado. 
mitológicas. Aquí se muestra con mayor claridad, si cabe, el carácter subjetivo de nuestra construcción, pues dichas formas mitológicas, arrojadas a la noche para ordenar determinadas regiones del cielo, y no precisamente las de menor relevancia, son pura obra de la imaginación, puros constructos fantásticos de los que no existe, ni jamás ha existido correlato alguno en la naturaleza. Una magnífica expresión gráfica de cuanto venimos exponiendo se puede apreciar en los mapas estelares, donde las estrellas que forman cada constelación se hallan unidas por líneas de trazos, cuya irrealidad es notoria, lo que les confiere esa particular y, al tiempo, configuración tan familiar. Y si de la cartografía de nuestro tiempo, supeditada radicalmente a las necesidades de exactitud y funcionalidad, trasladamos nuestra atención a las cartas y planisferios de cierta antigüedad, cuando los ingredientes de belleza artística todavía no habían quedado arrumbados, se hacen más patentes los elementos puramente formales aportados por la mente humana. Podemos entonces contemplar cómo ese mero conjunto de luces de la bóveda celeste se transmuta en escenario irreal donde, por obra de la imaginación, aparecen representados personajes, entidades y actividades míticas, junto a seres y objetos del mundo real, naturales unos y de carácter instrumental otros, creados por la industria del hombre. Resumiendo, la conjunción indisoluble de la forma puesta por el sujeto con los datos objetivos del mundo real, en este caso las estrellas, insertados en aquélla - simbiosis de materia y forma, al estilo aristotélico- configura el tipo de construcción en que consiste la constelación, cualquier tipo de constelación.

Entre esta construcción teórica, pero de la realidad, donde se aunan y complementan ambos elementos, el subjetivo y el objetivo, y la noción orteguiana del ser que venimos reflejando, nos parece encontrar una similaridad de tal calibre que permite convertir a la primera en modelo de la segunda. En este contexto de similitud cabe apreciar, casi con un cierto relieve intuitivo, cómo puede entenderse el ser propugnado por Ortega. El ser de las cosas, análogamente a cuanto ocurre con las constelaciones, es algo que el pensamiento "fabrica» — tal como manifiesta-, a partir de las cosas que nos rodean y cuyo trato con ellas conforma nuestra vida. Hay un pasaje de su trabajo Del Imperio Romano, referido a los teoremas, donde nos parece encontrar una extraordinaria similitud con lo que acontece con el ser, según ilustra el modelo de las constelaciones expuesto. Reduciéndonos al sentido de construcción del ente, tanto los teoremas de que nuestro autor habla, como esas figuras del firmamento antes descritas, casi vienen a ser equivalentes en cuanto a la particular luz que proyectan. He aquí el texto aludido: 
"los teoremas son figuras imaginarias que elaboramos con líneas de geométrica pureza. Mas la realidad no coincide nunca estrictamente con los teoremas. Y, sin embargo, no hay otra manera de entender la realidad que mirar sus facciones, siempre indecisas, al través de esos perfiles irreales fabricados previamente por nuestra fantasía. El teorema nos permite orientarnos en la confusión que es a simple vista, toda realidad, y nos permite inclusive medir con exactitud lo que haya de discrepancia entre ella y la tela de araña de nuestras ideas" (IR, VI, 90).

\section{Un modelo físico}

Igualmente podríamos considerar otro modelo que, con un ligero cambio de perspectiva, vendría a darnos un escorzo complementario de la visión proporcionada por el anterior. Si éste era de índole astronómica, ahora atenderíamos a uno de índole física. Se trataría del conocido fenómeno de la formación de imágenes reales por sistemas b́pticos, compuestos por lentes y/o espejos. En su foco, o en sus inmediaciones, algo que no hace al caso, fórmanse imágenes reales de objetos, que pueden ser percibidas por interposición de una pantalla. Para simplificar, nos circunscribimos a esta fase del proceso, evitando ulteriores complejidades y también toda connotación unida a la concepción del hombre como espejo de la naturaleza, cuya proyección epistémica devendría en la notoria teoría del reflejo. Nos centramos en configurar un posible modelo, caracterizado fundamentalmente por la equiparación entre el sujeto cognoscente orteguiano y la citada pantalla receptora donde se hace visible una imagen real. Lo objetivo aquí sería la luz, en su calidad de radiación electromagnética que, por medio de la acción de un sistema físico - del que no tenemos que ocuparnos- converge en su foco y produce la aludida imagen. Este modelo permite la exhibición de una analogla muy clara, aunque limitada a un sentido muy preciso. Se refiere a la función de patentizar que cumple tanto el sujeto como la pantalla. El postulado de la tesis metafísica, de que sin sujeto no hay ser, encuentra su correlato en el sistema óptico: en ausencia de una pantalla donde proyectarse, la imagen es inexistente.

Aunque sin duda oportuno en vista de la comprensión, no lo parece tanto detenernos y abundar sobre él con exceso. Excluyendo el sentido funcional descrito, quizá sea un modelo que no da cumplida cuenta de la faceta más profunda del problema. Las implicaciones ónticas, en particular, no hallan adecuada 
resonancia. El aspecto más opaco radica en lo objetivo. En este modelo óptico, la radiación electromagnética, la luz, es el elemento determinante del fenómeno de la formación de la imagen. Aunque la susodicha imagen no alcance a mostrarse, por ausencia de la pantalla, la radiación lumínica permanece presente en el medio transmisor. La pantalla sólo recoge, pasivamente, una imagen que, si bien inaparente, existe sin su concurso. Bajo este ángulo la analogía sugerida se distancia de los conceptos filosóficos que deseamos aclarar. Por el contrario, el modelo astronómico destaca la activa aportación del sujeto a la constitución del objeto.

El orbe opaco de las dificultades

Cabe ahora preguntarse acerca del progreso logrado en la comprensión de esta concepción metafísica. Si bien parece razonable suponer que se nos ha hecho más transparente, ¿podríamos igualmente afirmar, desde la perspectiva obtenida, que han quedado superadas las dificultades a que venimos aludiendo? Es de temer que subsistan imprecisiones y obscuridades de sentido, incompatibles con un sistema teorético coherente, a cuyo través explicarnos la realidad con mayor claridad. La complejidad del tema, al que tan gran número de páginas dedicara nuestro autor, nos disuade de emprender un estudio exhaustivo de todos los problemas implicados. Labor de tal envergadura excede los límites del presente trabajo. Será menester, pues, limitarnos a una serie de puntos que concitan los aspectos más sugestivos, por su carácter desazonadoramente enigmático, del asunto.

Quizá sea oportuno efectuar algunas consideraciones sobre el papel del sujeto en esta trama de poner 0 construir el ser, elemento clave de la noción orteguiana y que, posiblemente, condicione de manera decisiva todo su enfoque global.

\section{El papel del sujeto en la constitución del objeto}

En una primera aproximación, debemos advertir la existencia de un cierto sentido del poner, convertido en exigencia insoslayable de la actividad cognoscitiva del sujeto frente a la realidad, sea ella cual fuere. Cualquier cosa que se diga sobre algo implica un alguien que lo dice. Hay una imposibilidad manifiesta de 
pensar o conocer las cosas, los objetos que conforman la realidad -incluso en lo referente a la mera noticia de su existir-, en ausencia de un sujeto ante quien las mismas se presenten. El establecimiento de una relación bipolar, de naturaleza no simétrica, que incluya tanto al sujeto como al objeto, se muestra aquí como premisa absolutamente necesaria. A este sentido de posición, característico de una mera fenomenología del conocimiento, que no prejuzga la naturaleza de la realidad objeto de conocimiento, le atribuimos un carácter débih pues se halla inexorablemente implícito en toda relación epistémica $-\mathrm{y}$, bajo cierto ángulo, aun meramente vital - del hombre con el universo. Es un aspecto de la cuestión al que cabe hallar reflejos, como su nivel básico exige, en los textos de nuestro autor. A título de ejemplo puede aducirse el siguiente:

"pero, aparte de su verdad o su error, una teoría es un cuerpo de pensamientos que nace en un alma, en un espíritu, en una conciencia, lo mismo que el fruto en el árbol» (TNT, III, 231).

En efecto, este género de poner es algo que el espíritu humano elabora o produce, siéndonos a estos efectos irrelevante el procedimiento empleado para articular o ensamblar el conjunto de enunciados que conforman la teoría.

Mas enfocado lo anterior desde otra perspectiva, el sentido antes apuntado dilata su entidad, traspasando la delimitación epistemológica. El cambio operado nos conduce a una nueva noción, a la que podemos denominar fuerte, con anclaje en la dimensión ontológica. En ella, como no deja de ser evidente, va contenido y presupuesto el sentido anterior. Su cualidad primordial es quedar fuertemente escorada hacia el sobredimensionamiento de la posición por parte del sujeto. Esencialmente, nos habla del porqué y del cómo, de la razón y manera de construir o fabricar el precipitado intelectual al que denominamos teoría, en particular de aquellas surgidas en el ámbito de la ciencia y que tienen por correlato alguna región ontológica específica de la realidad. En esta implicación ineludible del sujeto para constituir el objeto -en este caso el ser-, radica todo el problematismo potencial de la cuestión. Lo que, a primera vista, parecía una simple cuestión periférica de poca importancia se nos transforma en una estructura metafísica fundamental. Nos hallamos ante implicaciones de mayor alcance que las meramente derivadas de una estricta fenomenología del conocimiento. La conclusión quizá más importante a extraer es el reflejo funcional y necesitario que adquiere la actividad teorética, como se subraya de continuo, conducente a que «no ha lugar a hablar de un ser si se 
abstrae de la vida humana” ( $Q V, 156)$. Repercusiones de este género, de trasfondo óntico, son las que marcan el rumbo de nuestra desazón. A este respecto nos parece muy significativo un pasaje de su "Filosofía pura (Anejo a mi folleto Kant)", porque acota el núcleo de problematismo. Dice el autor que las cosas, en cuanto ellas mismas,

«no son más ni menos, ni así, ni del otro modo, en suma, ni son ni no son. La medida de las cosas, su modo, su ni más ni menos, su así y no de la otra manera, es su ser y este implica la intervención del hombre" (AK, IV, 58).

Según cabe deducir, el ser no es ya meramente un en si que las cosas reales del mundo posean, independientemente de cualquier relación con el sujeto cognoscente y que éste se limite a descubrir.

El filósofo madrileño se sirve de una analogía para subrayar el papel inexcusable que desempeña el sujeto, ante el cuál se hace presente un ser que, sin su concurso, no llegaría a la existencia. Llama la atención sobre la relación de igualdad que se manifiesta entre dos manzanas y que, por más que sea una propiedad de éstas, objetiva, sólo surge cuando un sujeto ejecuta la comparación entre ambos objetos. El ejemplo no cubre íntegramente todas las facetas que serían pertinentes al caso, hallándose expuesta a una objeción no menuda, que vamos a dejar apuntada. Si bien la susodicha relación de igualdad cumple la misión encomendada de ilustrar el sentido de su proposición, resulta, empero, un tanto frustrante. Porque, concedamos de buen grado que la igualdad, producto de la comparación, no la "había» antes de esta operación. Mas afirmar lo mismo acerca del conjunto de notas que confieren su identidad propia a las manzanas, aparte y en ausencia de cualquier sujeto ante quien presentarse, puede parecer desmesurado. Puesto que sólo aparece el ser cuando el hombre se pregunta por él, es la interrogación de éste quien le hace surgir. Su poner-lo, su construir-lo aparece como el correlato de la dependencia del ser de lo real respecto del sujeto. Dependencia que, de esta manera, revela ya una tonalidad óntica. Parece que el sujeto asume la función de dispensador del ser. Aquí, no obstante, conviene extremar la cautela y establecer matizaciones pues entramos en un ámbito de sutilidad —-fondo del problema—, en el que es muy fácil desorientarnos. Tampoco cabe afirmar con rotundidad que Ortega haga del hombre el creador del ser. El sujeto no otorga la existencia al ser, al menos desde un cierto punto de vista, como nuestro pensador se cuida muy bien de insistir, p. e., en la nota, añadida en 1933, a su ensayo "La Filosofia 
de la Historia de Hegel y la historiologían, escrito en 1927 (IV, 531, n. 2), donde se subraya que el ser siempre es de la cosa, del objeto. Asumamos, pues, que el sujeto no confiere desde si mismo el ser a las cosas, imponiéndoles sus propias formas subjetivas, como ocurría en el neokantismo. Mas la reiteración sobre la inexorable dependencia de la aparición del ser respecto a la actividad cognoscente del sujeto conlleva un larvado problematismo. El simple hecho de la inserción de la aludida nota, varios años después de publicar dicho trabajo, nos hace entrever sus posibles dudas acerca una cierta dosis de ambigüedad o la implicación de un sentido equívoco respecto a posiciones subjetivistas neokantianas que convenía disipar.

En suma, la tesis orteguiana sobre el ser viene a decantanse en la consideración del mismo como una interpretación. Sentido manifestado en numerosos pasajes de sus obra, de entre los cuales sólo entresacamos uno, referido a la naturaleza y a las cosas:

"La naturaleza es una interpretación transitoria que el hombre ha dado a lo que encuentra frente a sí en su vida. ... Todas las cosas, sean las que fueren, son ya meras interpretaciones que se esfuerza en dar a lo que encuentra. El hombre no encuentra cosas, sino que las pone o supone» (HS, VI, 31-32).

$Y$ es precisamente esta concepción del ser como interpretación, perfectamente comprensible desde la perspectiva epistemológica estricta, la que nos conduce hacia el naufragio en un mar de dudas, según expresión tan cara a nuestro autor. Concedamos, pues, que el ser es la interpretación del hombre. Ahora bien, como correlato de la interpretación, obra del sujeto, está lo interpretado, lo otro que el sujeto, es decir, lo real. Ocurre que nos hallamos ante un desdoblamiento del significado del «ser". Por una parte, tendríamos el serpensado, la traducción de la realidad realizada por el sujeto y, por otra, el ser-real, opaco, que es aquel segmento de realidad que se interpreta. Todo induce a creer que gran parte de los equívocos y aun oscuridades que surgen en esta tesis metafísica provienen de la confusión entre ambos referentes del término, cuyo origen radique en la ausencia de una nítida delimitación entre los campos de lo epistémico y lo propiamente óntico. Y quizá todavía más que un problema de límites nos enfrentemos a cierto énfasis sobre el ser-pensado, en detrimento del ser-real. Puesto que el ser es construcción subjetiva, tal como afirma Ortega, ¿qué es o en qué consiste aquello que se interpreta, a lo que apunta dicho serinterpretación? Si a esto añadimos su rotunda afirmación de que sin sujeto no 
hay ser, desembocamos en el desvanecimiento del referente. El constituyente de la realidad, en cuanto tal, se nos diluye en la sombra y al ser de que Ortega nos habla corresponde una verdad puramente simbólica.

Tal vez sea conveniente referirnos a un fundamental esquema conceptual - expuesto ya en su primer libro, Meditaciones del "Quijote"-, convertido en instrumento para la captura de la auténtica realidad de las cosas, que se nos revela, así, constituida por la integración de dos planos o dimensiones. Por un lado, el mundo que consideramos más habitual, su dimensión patente, que se nos exhibe o presenta por intermediación de los sentidos, aunque no sólo por ellos. Ahora bien, tras este plano de lo real hay también un "trasmundo" latente, cuya manifestación solo es factible por su refracción en lo patente. Es ésta la dimensión - quizá habría que hablar en plural-, de profundidad de lo real, consistente en una "realidad virtual" o estructura de impresiones que el sujeto articula. Conviene destacar la afloración de aspectos polémicos en el desarrollo de este punto específico, todavía no bien clarificados, en los que ahora no cabe detenernos. Baste señalar una faceta que pudiera arrojar luz sobre nuestra exposición. En Meditaciones del "Quijote" (MQ, I, 329/337), al hilo de un análisis fenomenológico de la realidad del bosque, de aquello que constituye su verdadera esencia, Ortega nos va describiendo, ejemplificando de forma plástica, con su alusión a los sonidos provenientes de los arroyos y de las oropéndolas, en qué consisten ambos planos o dimensiones de la realidad que circunscribe al hombre. Centrando la atención en las «cualidades virtuales" de las cosas, las conformadoras del plano latente de la realidad, observamos que son producto de «un acto del sujeto", aunque, al tiempo, se resalta que no por ser latentes son menos reales. Más aquí nos hallamos ante dos rumbos divergentes que conviene distinguir. Para ello seguimos el análisis realizado por el profesor San Martín en su texto "Mundo y trasmundo" ". De acuerdo con el citado análisis habría dos modos de alcanzar la mencionada realidad virtual del mundo latente. Uno de ellos, expuesto por Ortega en sus aludidas Meditaciones, resulta de un acto "de interpretación ideal" por parte del sujeto, que "envuelve" de inmediato, automáticamente y sin deliberación conceptual alguna, las impresiones captadas - como los sonidos del ejemplo-, que reciben, así, una articulación que ellas, por sí, no contenían. Hay aquí un acto preteorético o antepredicativo, primario, por tanto, por parte del sujeto. En sus

11 Javier San MARTín, Ensayos sobre Ortega. UNED. Madrid, 1994. Págs. 36/42. 
Investigaciones psicológicas nos encontrariamos ya, según indicación del aludido profesor San Martín, con un esquema operativo de diferente cariz. En efecto, en ese último texto mencionado el susodicho desdoblamiento de la realidad en los planos patente y latente halla correspondencia - a mi modo de entender, con la segmentación entre el ser fenoménico y el ser real. El primero de estos queda definido por lo "constituido por lo presente en cuanto tal". Por el contrario, y en un contexto donde habla de la equiparación de calor y movimiento en Julio Roberto Meyer, con su asimilación al ser real se caracteriza muy precisamente al mundo de la física, donde «los valores numéricos son expresión de esas realidades latentes construidas como hipótesis por la razón" (IPs, XII, 353. Subrayado nuestro). Páginas más adelante, se refiere Ortega a una actividad del sujeto - que no deja de reiterar-, con respecto a su trato conceptual con las cosas. Por medio de aquélla aparecen en éstas nuevas cualidades, como son "sus identidades y distinciones, sus igualdades y desigualdades, sus correlaciones e irreferencias" (IPs, XII, 383). Reducido a lo esencial, puede decirse que las características surgidas en las cosas son «obras de nuestro pensar» (IPs, XII, 383). Estas palabras, a las que el subrayado de su autor confiere un mayor énfasis, ponen de manifiesto ese rasgo de construcción, atribuible al acto de la subjetividad. Mas es obligado resaltar que también ahora, como ya hiciera en el caso de Meditaciones, considera objetivas a las cualidades de lo real generadas en virtud del poner del sujeto. El resultado de ello no se limita, pues, a ser una mera elaboración subjetiva sin correlato alguno en la realidad. Merece destacarse, antes de abandonar este punto, la indeterminación que, según su expresada opinión de 1916, afecta a las notas de la realidad que venimos considerando: "Van y vienen de los objetos a nosotros, de nosotros a los objetos, sin que parezcan decidirse por ninguno de ambos bandos" (IPs, XII, 384).

Una hipótesis cabe inferir de este punto específico. Parece muy probable que Ortega ha situado al ser, por sus particulares características, entre las que destaca su ocultamiento, en la dimensión latente de lo real, en ese trasmundo que, aun perteneciendo a la realidad, es propiamente función de la subjetividad. Mas ocurre que si es claro que la realidad virtual mencionada se constituye en y por medio del sujeto, no lo parece tanto que se pueda extrapolar análoga operación al determinado caso del ser o consistencia de las cosas. Asimilar, pura y simplemente, la región del ser al orteguiano "trasmundo" de la latencia nos reconduce, una vez más, al punto controvertido de la cuestión.

A tenor de cuanto venimos exponiendo, cabe destacar que aquí se contiene, en forma larvada, una interesante faceta antropológica, a la que sólo podemos 
rozar. Desde esta dimensión el hombre asciende en la jerarquía ontológica, deviniendo en una especie de demiurgo menor, de segundo rango, al que se atribuye la misión de detentador de las llaves que dan acceso a la región del ser. Sin llegar a convertirse - según creemos - en "seńor del ser", aparenta asumir mayor importancia que la derivada del papel de "pastor del ser", como prefería atribuirle Heidegger.

\section{La disolución de la naturaleza en sí}

Esta tesis constructivista del ser, fundamentada en la conjunción indisoluble de sujeto y objeto, en su dependencia mutua, viene a superar el ser caracterizado como independiente. Discreta cuando opera en el campo estricto del conocimiento, parece harto disonante al proyectarse sobre la esfera óntica, suscitando incertidumbres de cierta amplitud. Dentro de su radio de acción se torna evidente que no podemos considerar una naturaleza en sí misma, independiente del hombre. Mas, por otro lado, se trata de una idea no excesivamente fácil de aceptar, como el mismo Ortega no deja de constatar. ¿Le es necesario al mundo, naturaleza o universo, el sujeto para existir? Toda la experiencia cognoscitiva acumulada testimonia en su contra.

En el Universo anterior a la existencia del hombre, que abarcaría períodos de tiempo casi inconmensurables, las interrelaciones ejecutadas por las cosas, es decir, las puestas en juego al margen del sujeto humano ante el que aquéllas aparecen, asumen ahora una singular dificultad. Como ocurriría que sin el hombre no hay ser, que las cosas no son - como dice Ortega-, puesto que no son para el sujeto, parece ineludible concluir que previamente a su aparición -o en todo lugar del Cosmos donde no haya vida consciente-, habrá de darse el ser de las cosas por inexistente. Problema de no pequeña magnitud, cuya sombra se alarga también hacia aquellos segmentos de la naturaleza todavía inaccesibles. Recordemos que planetas de nuestro propio Sistema solar, galaxias y otros objetos, como estrellas de neutrones o agujeros negros - por poner un breve ejemplo-, hasta fechas no muy lejanas quedaban al margen del conocimiento humano acerca de la Naturaleza. La consecuencia asume un cariz absurdo, evidenciándose la paradoja al considerar el ser de las cosas como aquello "permanente e inmutable" de las cosas, es decir su "conducta fija", "lo que son siempre" (QV, 155), o sea, efecto o proyección de la estructura interna propia de cada una. $\mathrm{Y}$, al tiempo, se intenta conjugar esa opinión con su tesis 
principal, contraria - como ya vimos-, a identificar el ser con la cosa, localizarle en ella o atribuirle su pertenencia a «ella sola». Nos hallamos ante un ser necesitario, tributario a la contribución del hombre. En su ausencia y desde este punto de vista, permanece en el misterio, cuando menos, que haya podido existir una Naturaleza en constante interacción entre sus elementos. Se trata de relaciones que únicamente han podido ocurrir bajo un complejo de leyes naturales de diferentes niveles de jerarquía. Todo lo cual exige, como condición previa e inexcusable, que las cosas posean una estructura o ser propio, en una palabra, un ser en sí.

El ejemplo de la igualdad entre dos manzanas, propuesto por Ortega para aclarar su posición, visto con anterioridad, nos sirve para concretar las dificultades implicadas. Dicha relación es objetiva, pero dependiente de un sujeto que ejecute la comparación. Únicamente se manifiesta ante un sujeto, en ausencia del cual no sólo carece de sentido hablar de aquélla, tesis de menor alcance y más razonable, sino que, si hemos interpretado correctamente sus palabras, ni siquiera existe. Y esto ya sí nos incita a la perplejidad. Vayamos al asunto: ¿se trata de una relación que sólo aparece ante el sujeto que la estudia, o, más bien, consistiría en una relación cuyo carácter sería ejecutivo? Imaginemos, a simple efecto expositivo, una hipotética situación en que ambas manzanas colgaran a sendos lados de una rama. La igualdad predicada podría, así, tener una proyección puramente física, equilibrando o desequilibrando -en conjunción con otros factores implicados- la citada rama, en función de esa igualdad que se ejecuta de forma espontánea al estar dichas manzanas inmersas en un determinado campo gravitatorio. Así pues, dicha relación de igualdad implica una realidad de mayor alcance que la reconocida por el filósofo. No sólo se trata de algo constitutivo de las cosas que puede, o no, aparecer ante un sujeto, sino que se traduce en resultados corpóreos o materiales operados sin la presencia de observador alguno. ¿Cabe mantener la atribución del ser a una determinada relación como aparecer, en respuesta a una interrogación subjetiva, cuando, al tiempo, sabemos que se ejecuta en ausencia del sujeto?

Estamos, así lo creemos, en el vórtice mismo del problema y quizá valga la pena demorarnos un poco más en su indagación. Intentemos suavizar un tanto las aristas de la objeción planteada por una naturaleza previa al hombre -0 a cualquier hipotética vida inteligente-, y que evolucionara por sí misma, hermética y huérfana de toda consciencia en que reflejarse. Para ello podríamos considerar el desarrollo del universo a la luz de un principio teleológico que consista precisamente en la aparición del sujeto cognoscente, como contraparte 
necesaria del propio cosmos para llegar a hacerse autocognoscible. Por supuesto, en esta visión finalista debería quedar incluido el denominado principio antrópico - más en boga en nuestros días-, al que podríamos ver como una cierta reedición modificada de la visión leibniziana del mejor de los mundos posibles. Ahora bien, ¿nos lleva esta corrección a reforzar de algún modo la posición de Ortega acerca del ser y del sujeto? A decir verdad, no estamos convencidos de que éste sea un camino conducente a eliminar toda dificultad. De hecho, prosiguiendo con este enfoque cosmológico, existe otra línea de reflexión de donde surge, según mi particular apreciación, un escollo de envergadura todavía mayor. Enunciado de modo sobrio, cabe decir que la casi totalidad de los cuerpos u objetos que aparecen en la bóveda del cielo se hallan situados a distancias absolutamente inmensas. Su luz —o radiación de cualquier longitud de onda-, vector que transporta la información aun de su mera su existencia, tarda en recorrer estos espacios cósmicos un tiempo que abarca desde los ocho minutos del Sol, hasta los miles de millones de años de las galaxias más alejadas detectables actualmente. Dejando de lado, por mor de la exposición, el caso de los componentes de nuestro Sistema solar — por «demasiado" cercanos-, resulta que todo lo que vemos en la faz de la noche es una escena fantasmagórica. El universo visible para el hombre es un conjunto de imágenes pertenecientes al pasado de los objetos celestes. En modo alguno exhiben su estado presente. En un sentido riguroso, que ninguna objeción ingenua puede disipar, consisten, pues, en puros cuerpos espectrales. Incluso, bien podrian haber desaparecido $y$, sin embargo, seguirían mostrándose ante nuestra mirada durante un tiempo que sería función de esas distancias que, bien mirado, son inconcebibles para la mente. Retornando al hilo de la argumentación, nos preguntamos: en ese contexto, ¿qué sentido tiene postular que sin sujeto no hay ser? $\mathrm{Si}$ nos referimos al ser de los objetos celestes de todo género antes de que su luz nos haya alcanzado, es obvio que dicho ser se ha tenido que estar ejecutando, precisamente para poder llegar a patentizársenos como tales objetos. En esta operación ninguna intervención ha tenido el sujeto. Y, por otra parte, de considerar el ser del objeto que el sujeto realmente está percibiendo, cuando mira al firmamento y actúa como tal sujeto en el mundo, entonces nos encontramos con la paradójica situación de que tampoco puede poner el ser a los objetos ya que estos, en sentido real, han dejado de tener existencia. De ellos sólo nos resta una mera imagen, un fantasma, en suma. Estamos ante múltiples refracciones del mismo problema: la existencia del ser de las cosas, en sus mutuas interacciones, al margen y en ausencia de sujeto 
alguno. Decantarse afirmativamente implica retornar a una visión de cuño realista que nuestro filósofo entiende superada por la Edad Moderna.

En síntesis, el dilema se reduce a considerar el ser como un rasgo óntico de las cosas, por tanto independiente del sujeto, con lo cual cerramos el círculo inicial del planeamiento; o bien se admite que la postulada construcción del ser por el sujeto - y su insoslayable relación de dependencia - sólo adquiere sentido al ubicarla en la esfera epistemológica. No vemos claro, hemos de confesarlo, donde Ortega sitúa su "replanteamiento del problema del ser". La literalidad de sus manifestaciones parece expresar que él coloca este punto conflictivo en una zona de intersección onto-epistemológica. Mas, por otro lado, algunos de sus textos parecen avalar la tesis de que en manera alguna se está tratando de los aspectos ónticos, lo que trasladaría la cuestión al puro ámbito gnoseológico.

En favor de esta última hipótesis milita la idea, fundamental en su pensamiento y explicitada debidamente, de la radical diferencia óntica que separa al hombre de las cosas, "de todos los demás entes del universo" (MB, V, 211). En tanto que el ser del hombre es algo que tiene que estar haciéndose permanentemente, pues "es la única y casi inconcebible realidad que existe sin tener un ser inmediatamente prefijado" (MB, V, 211), el ser de las cosas, al contrario, es su ser siempre, su inalterable identidad. Hemos de admitir que esta idea de una realidad fundamentalmente escindida, donde al sujeto se contraponen las cosas, como la piedra y el astro, "cuyo ser, cuya consistencia o contenido le es dado ya hecho" (EtG, V, 136), implica una radical independencia óntica del mundo respecto al sujeto. Sin embargo, precisamente por su claridad sería equívoco omitir su afirmación, expresada desde una perspectiva más distante y omniabarcadora de la vida, acerca de que uel hecho radical e irremediable es que el hombre viviendo se encuentra con que ni las cosas ni él tienen ser" (LM, XII, 95). No se limita a afirmar la tesis menor de que el hombre desconoce el ser de las cosas - su ser siempre lo que son-, sino que su declaración es de una mayor envergadura. En función de imperativos vitales, esa caracterización de sujeto y mundo o circunstancia desemboca en la necesidad de que el hombre, "en cada instante», tiene que "decidir su ser», lo cual incluye —en su opinión-, decidir también «el ser de las cosas" (LM, XII, 95).

Conviene ahora destacar igualmente un rasgo consustancial a su pensamiento que complica una tanto la cuestión. Se trata de su distanciamiento de 
la concepción subjetivista del idealismo de inspiración kantiana, reafirmando nuestro pensador su objetividad de tonalidad fenomenologica:

"pero hoy nos hallamos muy distantes de aquella radical paradoja y pensamos que la primera "condición de la posibilidad de la experiencia" o conocimiento de algo, es que ese algo sea, y que sea algo; por tanto que tenga forma, figura, estructura, carácter” (FHH, IV, 531).

No cabe inferir de ésta y de otras afirmaciones, como acabamos de comprobar, un ser propio de las cosas, independiente del hombre, y, en su virtud, declarar dirimida la cuestión? Desde luego, podríamos convenir en ello, aunque no sería una actitud rigurosa, pues si bien nos proporciona una solución plausible, dado que parece disolver las dificultades, nos deja abierto un interrogante sobremanera insidioso. De confinar nuestro tema a la órbita del conocimiento, donde quizá cabe aplicar en forma aproblemática el aludido sentido débil del poner, entonces carecería de verosimilitud el esfuerzo realizado por nuestro filósofo para tratar de convencernos de la novedad implicada en su aportación teórica. Es esta pertinaz actitud de Ortega la que nos lleva a la convicción de que él ha situado la cuestión del ser en el preciso lugar donde converge el cúmulo de dudas que venimos reflejando.

En efecto, el asunto es complejo, pues incluso reduciéndonos a la dimensión estrictamente gnoseológica, aflora un destacado aspecto problemático, paralelo al que reverbera desde la faceta ontologica. Cuando, no ha mucho, manifestábamos que la reconducción de la cuestión del ser al puro ámbito de la teoría del conocimiento la tornaba transparente, es de temer que estábamos simplificando en exceso, al menos en cierto sentido. Su presunta claridad proviene de un contraste radical entre lo óntico y lo epistémico. Mas también en el interior de este último campo nos vemos abocados a un particular núcleo enigmático, algo ya aludido. Esta reflejo de problematismo toma forma en una idea desazonadora. Según podemos inferir de algunos de sus textos de madurez, el hombre no llega del todo, en última instancia, a alcanzar con plenitud el conocimiento del ser verdadero de las cosas. Convertido el ser en "puro enigma», se abre un abismo que el sujeto no puede llegar a traspasar. La deconstrucción de la serie histórica de teorías sobre la realidad nos conduce a una zona incógnita, como sus palabras atestiguan:

«si desnudamos la circunstancia mundanal en que estamos de cuanto sobre ella hemos pensado y recibido, la hemos vaciado por completo de 
ser y en su lugar hemos dejado un enjambre de punzantes problemas» (LM, XII, 91).

$\mathrm{Y}$, sin embargo, a esta línea conceptual —de resonancia kantiana-, que también desarrolla en su obra Ideas y creencias, cabe hallar su contraposición en las afirmaciones que nos ha dejado - p.e., en RH40, XII, 234-, acerca de "despensar" lo real. Se trataría de eliminar aquellas formas que el sujeto pone en el conocimiento de la realidad, para poder, así, quedarnos con un resto, con aquel algo en que dicha realidad consiste. Ciertamente, tampoco en este punto parece demasiado factible conciliar ambas posturas. Desde el rumbo de pensamiento aquí aludido se tiende un puente sobre ese abismo abierto por la consideración del ser como enigma. Evadiéndose de la órbita del kantismo, se reconoce al hombre la capacidad de acceder al conocimiento del ser en sí. Pues ocurre, bajo este supuesto, que si el sujeto debe disolver todo lo construido o fabricado por el pensamiento es, precisamente, porque aquello que resta según cabe apreciar, no ya "puro enigma" indescifrable-, parece ser la faz auténtica que nos presenta lo real mismo. Subrayemos otro aspecto de la misma dificultad. Las cosas no nos manifiestan noticia alguna acerca de su ser, situado éste —como igualmente afirma-, en un "trasmundo", más allá y por detrás de las cosas o realidad. Ahora bien, si el ser, en consecuencia, es "interpretación" subjetiva, ¿cómo conciliarlo entonces con la afirmación de que, tras la deconstrucción de lo pensado, de la disolución del aporte del sujeto, podemos captar el ser verdadero de las cosas?

\section{Posibles rumbos de clarificación}

Conjeturamos que hemos dejado señaladas, en lo esencial, las facetas más aristadas de algunas nociones teóricas problemáticas. Sería factible, sin duda, rastrear otra serie de conceptos afines que exhiben similar tonalidad paradojica. Mas no dejan de conducir a idénticas dificultades, si bien vistas bajo diferente ángulo. Cabe ahora indagar potenciales afinidades, susceptibles de convertirse en vías de clarificación, si bien necesariamente debemos limitarnos a unas breves consideraciones.

En primer término hay que mencionar el interesante enfoque de R. Rodríguez, al que desde aquí parece oportuno remitir al lector. La Fenomenología tal vez se configure como una perspectiva adecuada para iluminar las espinosas 
cuestiones objeto de este trabajo. La filosofía orteguiana coloca la realidad radical - la vida-, como eje central de la interpretación última del universo. Desde ella, trata nuestro pensador de superar las sucesivas posiciones de la tradición, realismo e idealismo, intentando situarse en un nuevo nivel donde queden conciliados antagonismos seculares. El nervio de esta tesis integradora, que insinúa ya su sentido equívoco, adquiere significativo reflejo en el siguiente pasaje de sus Lecciones de Metafisica.

«el hombre y su circunstancia pelotean el problema del ser —se lo devuelven uno al otro-, lo que indica que el problema del ser es el de lo uno y lo otro, el del hombre y su circunstancia; el de todo" (LM, XII, 95).

El paralelismo entre esa concepción y el mundo de la vida husserliano parece evidente, sobre todo considerando el vuelco del ser hacia la órbita de las creencias, recogido por $\mathrm{R}$. Rodríguez en su artículo ${ }^{12} \mathrm{y}$ aludido páginas más atrás. Desde la fenomenología no cabe ya omitir la consideración de la subjetividad transcendental que constituye el ser del mundo. La constitución del mundo, en cuanto conjunto máximo de cosas, siempre abierto y potencialmente infinito, así como su sentido y validez de ser, acaecen en la zona de actuación propia de la subjetividad transcendental, a la que se accede tras el largo y laborioso camino de la epojé y la reducción trascendental. El pensador español parece tomar una ruta diferente, poniendo de manifiesto, a través de su análisis fenomenológico de la realidad, la función desempeñada por el sujeto en la articulación del plano de profundidad que lo real, necesariamente, debe poseer como tal objetividad. Tal vez fuese oportuno señalar al estrato de las creencias como el ámbito básico de la subjetividad, desde el que establecer —dentro de ciertos límites-, analogías con la región donde Husserl centra sus investigaciones. Sin embargo el ser propuesto por Ortega - por las razones ya aducidas al referirnos a la constitución histórica del Ente-, se desenvuelve en otra esfera distinta de la actividad humana, la de las ideas. Este ser-interpretación lo construye el sujeto en el ámbito teorético, bien sea en el dominio de las distintas ciencias particulares que estudian el mundo o lo realice, igualmente, en el específico campo filosófico. Ambos pertenecen al orbe de las ideas, matriz de los productos culturales propios del pensamiento teorizador y que Ortega contrapone muy nítidamente al mundo de las creencias, región ésta del psiquismo

12 Op. cit., págs. 45-46. 
donde moran las verdades latentes con las que "se cuenta" y que configuran para cada cuál la realidad misma. En resumen, a pesar de la patente similitud entre la estructura fundamental fenomenológica, del apriori de correlación entre subjetividad y mundo, y la concepción orteguiana de la vida como realidad radical, es probable que nos hallemos ante niveles diferenciados. El ser de que nos habla el filosofo madrileńo, a reserva de la hipótesis de su conversión - distanciada de sus momentos iniciales- en auténtica creencia, no pertenece, a mi entender, al ámbito trascendental en que Husserl busca fundamentar el sentido y validez del ser. Las concomitancias halladas, innegables, también pueden tornarse en velo encubridor de diferencias profundas, dada la suma complejidad de la fenomenología husserliana. Empero, este vector de afinidad entre ambas concepciones podría determinar, pese a las cautelas expresadas, una orientación satisfactoria, potencialmente capaz de conducirnos a una visión más coherente acerca del ser orteguiano.

Otro posible rumbo de aproximación se marcaría al hilo de las afinidades que cabe encontrar con la filosofia de Heidegger. Su influencia sobre Ortega es algo que se halla fuera de discusión. Y aun reducida a elemento de incitación para el desarrollo de las potencialidades latentes en su pensamiento mantiene extraordinario interés. Sobre esta línea temática podemos encontrar sugerentes ideas, p. e., en el excelente libro de $\mathrm{P}$. Cerezo, La voluntad de aventura ${ }^{13}$. No obstante, ésta es una vía en la que, por quedarnos más distante, no pretendemos entrar. Reste aquí, simplemente, indicada.

Sin menoscabo en ningún momento de los incuestionables influjos operantes desde el ámbito filosófico, quizá fuera conveniente, tomando un enfoque algo distinto, considerar el peso específico que cabe atribuir, según nuestra particular opinión, a sugestiones surgidas de otros cuadrantes. La explicación, siquiera parcial y complementaria de la perspectiva filosófica, residiría en las influencias recibidas desde el campo de la ciencia. El pensamiento orteguiano posee vigorosas raíces naturalistas, como el destacado ensayo del profesor Benavides ${ }^{14}$, centrado en aquellas que surgen desde la biología, pone de manifiesto. Ahora bien, el conocimiento que Ortega detentaba sobre la ciencia era de radio más dilatado, como lo reflejan innumerables pasajes de su obra. Destacar con

13 Particularmente el capítulo dedicado a "La confrontación Ortega y Heidegger». Págs. 302-338. Editorial Ariel. Barcelona, 1984.

14 Manuel BENAVIDES, De la ameba al monstruo propicio. Universidad Autónoma de Madrid, 1988. 
cierto detalle esta cuestión es tarea de la que me ocupado en otro lugar, a la que aquí sólo cabe aludir ${ }^{15}$. El curso de nuestro rumbo conduce al orbe de la ciencia física, convertida en punta de lanza del saber de su tiempo. Estimo esclarecedoras las concomitancias o paralelismo de orientación que cabe establecer entre la teoría metafísica de referencia y determinados hechos físicos, del mundo real por tanto, considerados a la luz de la interpretación cuántica de la naturaleza. Las nuevas teorías físicas, operantes con plenitud a partir del año 27 , introducían por su parte una ruptura francamente radical con las concepciones de la física clásica hasta entonces admitida. El influjo de la ciencia más avanzada de sus días posiblemente contribuya a hacernos entender el afianzamiento del filósofo en las problemáticas tesis onto-epistemológicas reseñadas. Bajo esta perspectiva, la radicalidad de las ideas orteguianas extraería su sustancia innovadora de la auténtica realidad, de la verdadera constitución de la materia del Universo, en sus niveles microfísicos, que la ciencia de vanguardia, aun con las crisis de fondo asociadas, iba poniendo al descubierto ante la atónita mirada del hombre contemporáneo.

Dos aspectos fundamentales de la nueva visión física conviene destacar, por su contribución a la relevante analogía que cabe establecer entre la tesis metafisica del "ser-relacional» y lo que parece acontecer en el microcosmos cuántico. Uno sería el papel que el sujeto asume en la determinación de las partículas subatómicas sometidas a observación. El sujeto se convierte, desde la citada interpretación de la naturaleza, en elemento integrante del conocimiento. Ocurre que su interacción con la naturaleza que estudia alcanza una nueva dimensión cuyo resultado inevitable es perturbar los sistemas microfísicos al intentar su medición. Resulta, pues, que al hombre no le es posible acceder -en este nivel - al conocimiento de la naturaleza tal cual sea en sí misma. Lo que es más, ni tan siquiera puede esta realidad mostrar su propia faz, la que posee sin el concurso del sujeto. La misma intervención humana se torna decisiva a la hora de que las partículas observadas se decanten por una de las posibilidades del conjunto de sus potencialidades cuya expresión es su función de onda. Las superposiciones de estado de las partículas no se resuelven sino ante la intervención de un sujeto observador que, en cuanto tal, altera el libre curso de las mismas, haciendo que dicha función de onda se colapse en unos resultados concretos y determinados posibles de medir, por tanto, de conocer. Objeto y sujeto se hallan en mutua dependencia, adquiriendo este último una función

$15 \mathrm{La}$ Ciencia en el pensamiento de Ortega (Tesis doctoral). UNED. Madrid, 1996. 
de copartícipe - y aun inductor - ineludible en el conocimiento y constitución del fenómeno estudiado.

La otra faceta del asunto consiste en que, correlativamente, el objeto diluye su consistencia. Sus valores de posición, momento, velocidad, etc., se ven afectados por relaciones de incertidumbre, presentando su conjunto un cierto rango de indefinicion. De esta forma "no representan propiedades objetivas de un cuerpo" ${ }^{16}$. Condensando al máximo las conclusiones, cabe afirmar que desde esta concepción cuántica, operante a nivel de partículas elementales, "no cabe una descripción inequívoca de la naturaleza" ${ }^{17}$. Lo que es más, es la propia imagen de la naturaleza que nos proporciona la ciencia natural exacta la que acaba desvaneciéndose, pues, como afirma uno de los físicos más insignes de la época, "la imagen no lo es en último análisis de la Naturaleza en sí; se trata de una imagen de nuestra relación con la Naturaleza" ${ }^{18}$. Acaece, pues, que en una parcela profunda del mundo material el referente real también se oscurece, pasando a ser su conocimiento meramente simbólico, como Ortega no deja de subrayar.

Nuestra exposición llega a su término constatando que las cuestiones enigmáticas, planteadas o entrevistas a lo largo de estas líneas, permanecen irresueltas. Claro que, a tenor de lo expuesto, difícilmente podía ser de otra manera. Fruto cultural de una determinada época, y precisamente por estar «a la altura de los tiempos", la teoría orteguiana del ser participa de las dificultades afloradas en el pensamiento contemporáneo, que alcanzaban una magnitud hasta entonces desconocida. De hecho, el problematismo implicado por algunos aspectos de la física cuántica permanece hasta nuestros días como un núcleo irreductible al conocimiento y ello pese a que esta ciencia haya conseguido el altísimo desarrollo que caracteriza a los tiempos presentes.

\section{Nota bibliográfica}

Salvo mención expresa, como los trabajos publicados bajo el título ¿̨ué es conocimiento?, procederemos en la forma habitual de hacer referencia a los textos de Ortega,

16 Frederick SUPPE, La estructura de las teorias cientificas. Pág. 215. Editora Nacional. 1974.

17 Op. cit., ibid.

18 Werner Heisenberg, La imagen de la Naturaleza en la fisica actual. Pág. 26. Rowohlt Verlag. Hamburgo, 1955.- Ediciones Orbis. Barcelona, 1985. 
indicando el tomo de las Obras completas en números romanos y las páginas en cifras arábigas, siendo precedidos por una sigla identificativa del libro, ensayo, o artículo, a tenor de la siguiente relación:

- Meditaciones del "Quijote", 1914: MQ.

- Investigaciones psicológicas, 1915-16: IPs.

- El tema de nuestro tiempo, 1923: TNT.

- «La Filosofia de la Historia de Hegel y la historiología», 1928: FHH.

— «Filosofía pura (Anejo a mi folleto Kant), 1929: AK.

- ¿Qué es filosofia?, 1928-1929: QF.

— «obre la realidad radical», 1930: RR. (*)

- "¿Qué es la vida?", 1930-1931: QV. (*)

— "Atisbos de historia de la Filosoffa", 1930-1931: AHF. (*)

- Unas lecciones de Metafisica, 1932-1933: LM.

- En torno a Galileo, 1933: EtG.

- Ideas y creencias, 1934: IC.

— "Misión del bibliotecario», 1935: MB.

- Historia como sistema, 1935: HS.

- "La razón histórica», Buenos Aires, 1940: RH40.

- Del Imperio romano, 1941: IR.

- Apuntes sobre el pensamiento: su teurgia y su demiurgia, 1941: AP.

— "La razón histórica”, Lisboa, 1944: RH44.

— "Comentario al Banquete de Platón», 1946: CB.

- La idea de principio en Leibniz, 1947: IPL.

(*) Incluidos en el libro ¿Qué es conocimiento? Revista de Occidente en Alianza Editorial. Madrid, 1992. 